\title{
Effect of Chromium(VI) on Serum Iron and Removal of its Toxicity by Combining Deferasirox and Deferiprone Chelators in Rats
}

\author{
${ }^{1}$ S. Jamil A. Fatemi, ${ }^{1}$ Marzieh Iranmanesh and ${ }^{2}$ Faezeh Dahooee Balooch \\ ${ }^{1}$ Department of Chemistry, Faculty of Sciences, Islamic Azad University, Kerman Branch, Kerman, Iran \\ ${ }^{2}$ Department of Chemistry, Faculty of Sciences, Shahid Bahonar University of Kerman, Kerman, Iran
}

Received 2013-09-26, Revised 2013-10-21; Accepted 2013-10-30

\begin{abstract}
The present research is aimed to characterize the potential efficiency of two chelators after chromium(VI) administration for 60 days following two doses of 15 and $30 \mathrm{mg} \mathrm{kg}^{-1}$ chromium(VI) per body weight daily to male rats. However, the hypothesis that the two chelators might be more efficient as combined therapy than as single therapy in removing chromium(VI) from bood serum was considered. In this way, two known chelators deferasirox and deferiprone were chosen and tested in the acute rat model. Two chelators were given orally as a single or combined therapy for a period of one week. Chromium(VI) and iron concentrations in blood were determined by flame atomic absorption spectroscopy method. Chromium is one of the most widely used industrial metals. Several million workers worldwide are estimated to be exposed to chromium compounds in an array of industries. Chromium(VI) is more readily absorbed by both inhalation and oral routes. Ingestion of large amounts of chromium(VI) can lead to severe respiratory, cardiovascular, gastrointestinal, hepatic and renal damage and potentially death. The combined chelation therapy results show that deferasirox and deferiprone are able to remove chromium(VI) ions from bood while iron concentration returned to the normal level and symptoms are also decreased.
\end{abstract}

Keywords: Combined Therapy, Deferasirox, Deferiprone, Chromium, Iron

\section{INTRODUCTION}

Chromium is an important metal, which is used in a variety of industrial applications e.g. textile dying, tanneries, metallurgy, metal electroplating, wood preserving and preparation of chromate compounds. It hence, large quantities of chromium have been discharged into the environment due to accidental releases or inadequate precautionary measures (Kimbrough et al., 1999). The chemical and toxicological behaviors of chromium depend on its oxidation state. The most important concern from the human health point of view is chromium(VI) for both acute and chronic exposures
(ATSDR, 1998). Chromium(VI) is known to enter cells readily via non-specific anion channels and it is thereafter reduced by intracellular reductants to the more stable $\mathrm{Cr}$ (III) with the concomitant formation of reactive intermediate species of $\mathrm{Cr}, \mathrm{Cr}(\mathrm{V})$ and (IV) and Reactive Oxygen Species (ROS). These reactive species can cause DNA damage and lipid peroxidation (Bagchi et al., 2002; O'Brien et al., 2003). Thus, removal of chromium and especially Chromium(VI), is an essential pollution abatement process that should be applied to all industrial effluents that contain this contaminant.

One way to remove toxic elements, such as chromium, from the body is chelation therapy. Chelation

Corresponding Author: S. Jamil A. Fatemi, Department of Chemistry, Faculty of Sciences, Islamic Azad University, Kerman Branch, Kerman, Iran 
therapy involves the use of ligating drugs that bind metal for the treatment of potentially fatal conditions. These ligands promote the excretion and subsequent depletion of this transition metal in biological systems. Clinical evaluations of some chelators for removal of toxic metal ions in rats have been previously reported by (Amiri et al., 2007; Fatemi et al., 2007; 2009; Saljooghi and Fatemi, 2010; Tubafard and Fatemi, 2008). These chelating agents consist of a range of bidentate, tridentate and hexadentate ligands in which two, three or six atoms are able to coordinate, respectively (Clarke and Martell, 1992). In this procedure, chelator is added to the blood through a vein or administered orally in order to remove toxic element. Deferasirox (4-[3,5-bis(2-hydroxyphenyl)1,2,4-triazol-1-yl]-benzoic acid, or ICL670; Fig. 1 was first reported in 1999 (Heinz et al., 1999). It is a tri-dentate chelator with high selectivity for $\mathrm{Fe}^{3+}$. It selectively binds $\mathrm{Fe}^{3+}$ over $\mathrm{Fe}^{2+}$ and shows little affinity for other divalent ions such as $\mathrm{Zn}^{2+}$ or $\mathrm{Cu}^{2+}$ (Steinhauser et al., 2004). In vivo, this selectivity is demonstrated by conserved plasma $\mathrm{Zn}$ and $\mathrm{Cu}$ levels in patients taking deferasirox and while its efficacy is rather low for inducing negative iron balance, it is effective and well tolerated (Nisbet-Brown et al., 2003). In 2005 deferasirox became the first FDAapproved oral alternative for treatment of iron overload and was subsequently approved in the EU in 2006 (Yang et al., 2007). The other chelator for iron overload is deferiprone (1,2-dimethy1-3hydroxypyride-4-one) that has been shown in Fig. 2. Deferiprone can be given orally and its important property is its ability to penetrate cells, coordinate iron, forming a neutral complex, which is also capable of permeating membranes (Glickstein et al., 2006). This kind of therapy by combining two chelators is based on the assumption that various chelating agent mobilize toxic element from different tissue compartments and therefore better results are expected (Flora et al., 1995). Results of this kind of combined chelation therapy has been confirmed by (Amiri et al., 2007; Fatemi et al., 2007; 2009; 2011; 2012; Tubafard and Fatemi, 2008; Tubafard et al., 2010). The aim of this study was to test the chelation potency of deferasirox and deferiprone in combination, given to animals after chromium loading. Testing was performed by using a chronic poisoning model on rats with individual and combined chelators given shortly after chromium application.

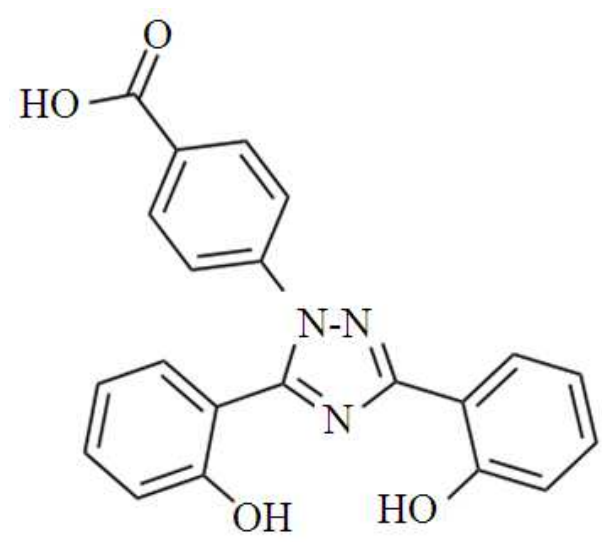

Fig. 1. Chemical structure of deferasirox

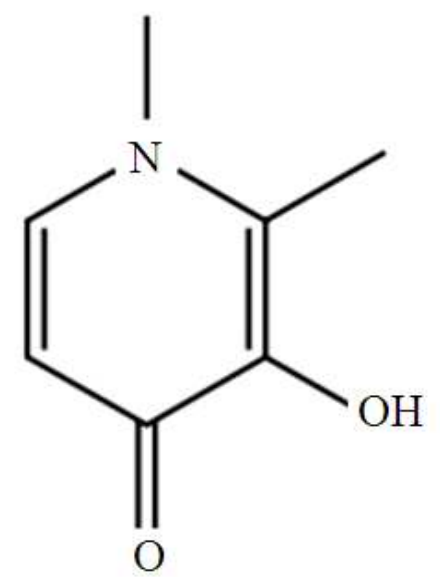

Fig. 2. Chemical structure of deferiprone

\section{MATERIALS AND METHODS}

\subsection{Apparatus}

A Varian Atomic Absorption Spectrometer (F AAS) was used for measurement of chromium and iron concentrations in blood serum.

\subsection{Maintenance of the Animals}

Male wistar rats were obtained from Razi Institute (Karaj, Iran). They bred in animal house at Kerman Neuroscience Research Center, Kerman, Iran. The rats were maintained under a controlled light: Dark (12:12h) schedule at $23 \pm 1^{\circ} \mathrm{C}$ and humidity of $55 \%$. The animals were assigned randomly to control and treated groups and were kept in well-cleaned sterilized cages. The rat food was purchased from Razi Institute. This study was approved by the ethics committee of Shahid Bahonar 
University of Kerman, Iran and Kerman Neuroscience Research Center, Iran.

\subsection{Materials}

$\mathrm{K}_{2} \mathrm{Cr}_{2} \mathrm{O}_{7}$, deferiprone and other materials were purchased from Merck Chemicals Co. and deferasirox was purchased from Novartis Co. (Basel, Switzerland).

\subsection{Experimental Design}

In our model, we used two different doses of chromium followed by an early administration of chelating agent. Experiments were performed on 7week-old wistar male rats.

There were slight differences between the groups in the initial body weight of the rats (mean $200 \mathrm{~g}$ ), but at the end of chromium administration experiment, those given chromium in their diet had significant weight loss (Table 1). Comparison of the weights in this experiment shows dietary treatment affected the food intake, whereby animals given normal diet consumed more food than those given chromium. Also because of the slight (but significant) differences in body weight of rats at the start of study, the results can be influenced by the initial classification and assignment of rats to treated groups. Therefore, the day 1 groups' body weights are notable and they must be considered. Consequently after acclimatization of animals, we assigned them randomly to control and treated groups.

Two doses of 15 and $30 \mathrm{mg} \mathrm{kg}^{-1}$ chromium(VI) per body weight were given to treated groups for 60 days. Chelation therapy was carried out after chromium application.

In this part of the research, treated groups were divided into five groups: Before chelation therapy, without chelation therapy, chelation therapy with deferasirox, chelation therapy with deferiprone and chelation therapy with Deferasirox+deferiprone (Table 2). Chelators (Deferasirox and deferiprone) were given orally after chromium application during 1 week. Doses of Deferasirox and deferiprone were 140 and $300 \mathrm{mg} \mathrm{kg}^{-1}$ body weight, respectively. Observed chromium toxicity symptoms in rats have been removed in short term (7 days) after drug administration. After chelation therapy, these rats were anesthetized with ether vapor and immobilized by cervical dislocation. Animals were sacrificed by exsanguinations from abdominal aorta; and bood serum samples were collected for determination of chromium content. Then, the residue was diluted with water to $10 \mathrm{~mL}$ volume.

Table 1. Body weights over 60 days for the rats in different groups (values are mean for the number of observation in parentheses)

\begin{tabular}{llll}
\hline Group & Control & $\begin{array}{l}\text { Low dose drinking } \\
\text { of chromium }\end{array}$ & $\begin{array}{l}\text { High dose drinking } \\
\text { of chromium }\end{array}$ \\
\hline Initial body weight $^{\mathrm{a}}(\mathrm{g})$ & $205 \pm 7(5)($ day 1$)$ & $200 \pm 4(5)($ day 1$)$ & $195 \pm 3(5)($ day 1$)$ \\
Final body weight $^{\mathrm{a}}(\mathrm{g})$ & $275 \pm 6(5)($ day 60$)$ & $255 \pm 8(5)($ day 67$)$ & $225 \pm 7(4)($ day 67$)$ \\
\hline
\end{tabular}

${ }^{\mathrm{a}}$ Mean of five determination \pm standard deviation

Table 2. Classification of animals

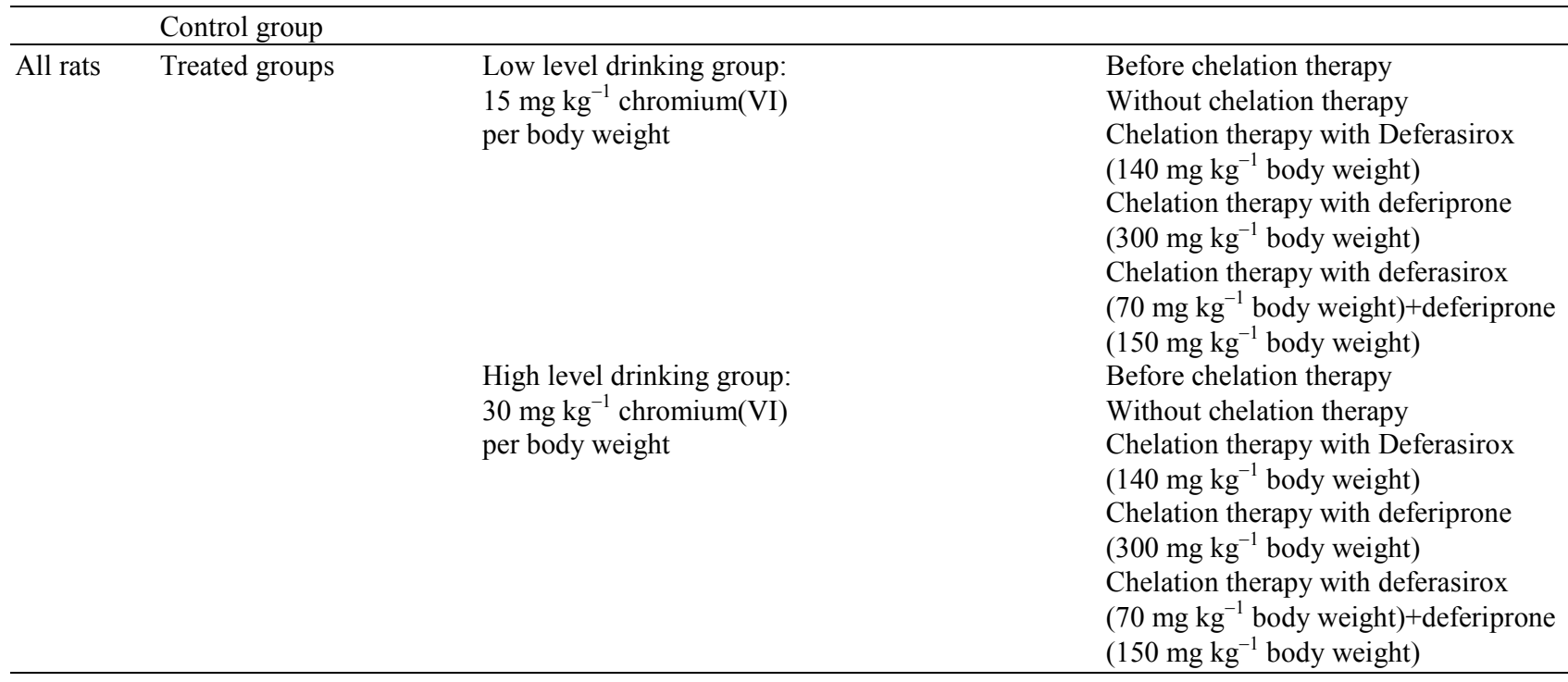




\subsection{Statistical analysis}

Determination of chromium and iron in samples were carried out by FAAS. The values are expressed as mean values (at least three separate determinations) \pm Standard Error of the Mean (SEM). The data were subjected to statistical analysis by Student's t-test; $\mathrm{p}<0.05$ was considered significant.

\section{RESULTS}

Results of chromium raising and iron reduction in blood samples of two chromium(VI) doses groups were statistically different. The chromium accumulation in blood serum at high dose was more than the group at low dose. A significant difference between control and treated groups was observed. The general symptoms of toxicity appeared after 60 days of administration of chromium. Abnormal clinical signs in animals were observed as follows: Irritability, weakness and loss of hair. Also the body weights of all animals were significantly decreased.

After the chelation therapy, the iron and chromium levels in both different doses groups showed that chromium levels present in blood serum were significantly reduced whereas, iron concentration returned to the normal level and the symptoms also reduced. Iron level is lowest in the group having the highest chromium concentration, which is probably because of a significant interference that could take place by chromium through iron uptake mechanism. There is statistical difference between deferasirox and deferiprone in reducing the amount of chromium in blood serum. The $t$-test was applied to the results assuming the certified values are the true values.

At both lower and higher doses, deferasirox + deferiprone groups were more effective than deferiprone or deferasirox. Comparison of mono and combining chelators in this experiment shows more efficiency of deferasirox + deferiprone in reducing the chromium level in blood serum. The results of chromium distribution before and after chelation therapies in blood serum are shown in Table 3.

Furthermore, iron concentration after administration of chromium was significantly decreased. The difference between iron values before and after chelation therapy is notable. Combination of deferasirox + deferiprone shows more efficiency in returning iron level to normal state. The results of iron concentrations before and after chelation therapies are summarized in Table 4.

In order to investigate the effect of passing time in removing chromium from the body spontaneously, one group was treated as without chelation therapy. The results of chelation therapy group are shown in Table 3 and 4. Comparison of the results obtained from both (before and without chelation therapy) groups are indicating that the passing time has no significant effect on removal of chromium.

Table 3. The results of chromium level before and after chelation therapies ${ }^{\mathrm{a}}$

\begin{tabular}{llllll}
\hline Group & $\begin{array}{l}\text { Before chelation } \\
\text { therapy }\end{array}$ & $\begin{array}{l}\text { Without } \\
\text { chelation therapy }\end{array}$ & $\begin{array}{l}\text { Chelation therapy } \\
\text { with deferiprone }\end{array}$ & $\begin{array}{l}\text { Chelation therapy } \\
\text { with deferasirox }\end{array}$ & $\begin{array}{l}\text { Combination } \\
\text { therapy }\end{array}$ \\
\hline blood (mg/L) Control & $0.102 \pm 0.023$ & - & - & - & - \\
Drinking (low dose) & $0.252 \pm 0.024$ & $0.244 \pm 0.019$ & $0.183 \pm 0.021$ & $0.142 \pm 0.011$ & $0.102 \pm 0.014$ \\
Drinking (high dose) & $0.291 \pm 0.031$ & $0.283 \pm 0.017$ & $0.203 \pm 0.018$ & $0.174 \pm 0.022$ & $0.142 \pm 0.015$ \\
\hline
\end{tabular}

${ }^{\mathrm{a}}$ The number of rats in each group were five; results are represented as arithmetic means \pm SEM, significant at $\mathrm{p}<0.05$ when compared with control

Table 4. The results of iron level before and after chelation therapies

\begin{tabular}{llllll}
$\begin{array}{l}\text { Group } \\
\text { blood }(\mathrm{mg} / \mathrm{L})\end{array}$ & $\begin{array}{l}\text { Before chelation } \\
\text { therapy }\end{array}$ & $\begin{array}{l}\text { Without } \\
\text { chelation therapy }\end{array}$ & $\begin{array}{l}\text { Chelation therapy } \\
\text { with deferiprone }\end{array}$ & $\begin{array}{l}\text { Chelation therapy } \\
\text { with deferasirox }\end{array}$ & $\begin{array}{l}\text { Combination } \\
\text { therapy }\end{array}$ \\
\hline Control & $0.981 \pm 0.021$ & - & - & - & - \\
Drinking(low dose) & $0.173 \pm 0.029$ & $0.191 \pm 0.021$ & $0.214 \pm 0.017$ & $0.394 \pm 0.014$ & $0.944 \pm 0.023$ \\
Drinking (high dose) & $0.142 \pm 0.027$ & $0.163 \pm 0.017$ & $0.292 \pm 0.012$ & $0.413 \pm 0.019$ & $0.963 \pm 0.026$ \\
\hline
\end{tabular}

The number of rats in each group were five; results are represented as arithmetic means \pm SEM, significant at $\mathrm{p}<0.05$ when compared with control 


\section{DISCUSSION}

The aim of the present work was to evaluate the ability of combined deferasirox and deferiprone in removing chromium from blood. Chromium(VI) compounds are widely used in the chemical industry as ingredients and catalysts in pigments, metal plating and chemical synthesis. Chromium(VI) can also be produced when welding on stainless steel or chromium(VI)painted surfaces. The major health effects associated with exposure to chromium(VI) include lung cancer, nasal septum ulcerations and perforations, skin ulcerations and allergic and irritant contact dermatitis. Many studies have now reported the high absorption, distribution, long-term efficacy and safety of deferasirox and deferiprone in removing some toxic metal ions and treating iron overload in patients with $\beta$-thalassaemia major (Cappellini, 2008; Neufeld, 2006). Deferasirox can penetrate membranes easily and possesses good oral availability. Indeed, when orally administered to hypertransfused rats, deferasirox promotes the excretion of chelatable iron from hepatocellular iron stores, four to five times more effectively than desferrioxamine (Hershko et al., 2001). Deferiprone can be given orally and its important property is its ability to penetrate cells, coordinate iron, forming a neutral complex, which is also capable of permeating membranes (Glickstein et al., 2006). At present, combination therapy with deferiprone and desferoxamine, that is highly selective for iron(III) under biological conditions is reported to be the most effective treatment for many patients (Galanello et al., 2010). The combined therapy procedure is likely to enhance iron excretion, target specific iron compartments, minimize side-effects (by virtue of the use of lower doses), facilitate individualization of therapy and improve compliance (Ma et al., 2012). Recently successful chelation therapy using both deferasirox and deferiprone has been reported (Voskaridou et al., 2011). In this investigation, a shortterm experimental model was used in order to speed up the preliminary testing procedure. The effects of these chelators on chromium and iron levels were remarkable. Gastrointestinal absorption and uptake of chromium after oral exposure show the accumulation of chromium in blood serum as well as decrease of iron concentration in it. In order to understand the abilities of mentioned chelators, we have done the distribution of chromium and observed accumulation of direct toxic effect of chromium in the blood serum. After administration of chelating agents, the chromium content returned to nearly normal level of control group, which indicates that deferasirox+deferiprone effectively increases the elimination of chromium in rats and the symptom was greatly decreased. A comparison of the results obtained from with and without chelation therapies indicate that combined (deferasirox + deferiprone) therapy increases the elimination of chromium effectively.

In comparison to the results obtained by (Fatemi et al., 2007; 2009; 2011; 2012; Amiri et al., 2007; Tubafard and Fatemi, 2008; Tubafard et al., 2010) it can be concluded that the two chelators (deferasirox+deferiprone) are more efficient as combined therapy than single therapy in removing chromium from rat blood. Therefore deferasirox + deferiprone could eliminate chromium from blood serum of rats and treat side-effects and the general symptoms of toxicity caused by chromium.

Thus combination of deferasirox + deferiprone represent a promising drug of chromium-mobilizing agent. Our results showed that this procedure might be useful for preliminary testing of the efficiency of chelating agent in removing chromium. Even though their toxicities are relatively low, in feuture basic preclinical research is needed before they could be recommended for human administration.

\section{ACKNOWLEDGEMENT}

The researchers are thankful to the head and director of Kerman Neuroscience Research Center and Islamic Azad University, Kerman Branch Faculty Research Funds for their support of these investigations.

\section{REFERENCES}

Amiri, A., S.J. Fatemi and S.N. Fatemi, 2007. Removal of thallium by combining desferrioxamine and deferiprone chelators in rats. Biometals, 20: 159163. PMID: 16927173

ATSDR, 1998. Toxicological profile for chromium. Public Health Service. US Department of Health and Human Services, Atlanta, GA.

Bagchi, D., S.J. Stohs, B.W. Downs, M. Bagchi and H.G. Preuss, 2002. Cytotoxicity and oxidative mechanisms of different forms of chromium. Toxicology, 180: 5-22. PMID: 12324196

Cappellini, M.D., 2008. Long-term efficacy and safety of deferasirox. Blood Rev., 22: 35-41. PMID: 19059055

Clarke, E.T. and A.E. Martell, 1992. Stabilities of 1, 2dimethyl-3-hydroxypyrid-4-one chelates of divalent and trivalent metal ions. Inorganica Chim. Acta, 19: 57-63. DOI: 10.1016/S0020-1693(00)80327-8 
Fatemi, S.J., A. Amiri, M.H. Bazargan, S. Tubafard and S.N. Fatemi, 2007. Clinical evaluation of Desferrioxamine (DFO) for removal of thallium ions in rats. Int. J. Artif. Organs, 30: 902-905. PMID: 17992651

Fatemi, S.J., A.S. Saljooghi, F.D. Balooch, M. Iranmanesh and M.R. Golbafn, 2011. Chelation of cadmium by combining deferasirox and deferiprone in rats. Toxicol. Indus. Health, 27: 371-377. DOI: 10.1177/0748233710388451

Fatemi, S.J., A.S. Saljooghi, F.D. Balooch, M. Iranmanesh and M.R. Golbafan, 2012. Removal of cadmium by combining deferasirox and desferrioxamine chelators in rats. Toxicol. Indus. Health, 28: 35-41. DOI: 10.1177/0748233711403192

Fatemi, S.J., S. Tubafard and B. Nadi, 2009. Evaluation of the effect of cadmium on rat organs and investigation of diethyl carbamate as an oral drug in treatment of cadmium toxicity. Med. Chem. Res., 18: 179-186. DOI: 10.1007/S00044-008-9118-Z

Flora, S.J.S., R. Bhattacharyan and R. Vijayaraghavan, 1995. Combined therapeutic potential of meso dimercaptosuccinic acid and calcium edentate on the mobilization and distribution of lead in experimental lead intoxication in rats. Fundamental Applied Toxicol., 25: 233-240. PMID: 7665007

Galanello, R., A. Agus, S. Campus, F. Danjou and P.J. Giardina et al., 2010. Combined iron chelation therapy. Ann. New York Acad. Sci., 1202: 79-86. DOI: $10.1111 /$ j.1749-6632.2010.05591.x

Glickstein, H., R. BenEl, G. Link, W. Breuer and A.M. Konijn et al., 2006. Action of chelators in ironloaded cardiac cells: Accessibility to intracellular labile iron and functional consequences. Blood, 108: 3195-3203. PMID: 16835377

Heinz, U., K. Hegetschweiler, P. Acklin, B. Faller and R. Lattmann et al., 1999. 4-[3,5-Bis (2hydroxyphenyl)-1,2,4-triazol-1-yl]-benzoic acid: A novel, efficient and selective iron (iii) complexing agent. Angewandte Chemie Int. Edn., 38: 25682571 .

DOI: $10.1002 /(\mathrm{SICI}) 1521-$ 3773(19990903)38:17<2568::AIDANIE2568>3.0.CO;2-C

Hershko, C., A.M. Konijn, H.P. Nick, W. Breuer and Z.I. Cabantchik et al., 2001. ICL670A: A new synthetic oral chelator: Evaluation in hypertransfused rats with selective radioiron probes of hepatocellular and reticuloendothelial iron stores and in iron-loaded rat heart cells in culture. Blood, 97: 1115-1122. PMID: 11159545
Kimbrough, D.E., Y. Cohen and A.M. Winer, 1999. A critical assessment of chromium in the environment. Critical Rev. Environ. Sci. Technol., 29: 1-46. DOI: 10.1080/10643389991259164

Ma, Y., T. Zhou, X. Kong and R.C. Hider, 2012. Chelating agents for the treatment of systemic iron overload. Curr. Med. Chem., 19: 2816-2827. DOI: 10.2174/092986712800609724

Neufeld, E.J., 2006. Oral chelators deferasirox and deferiprone for transfusional iron overload in thalassemia major: New data, new questions. Blood, 107: 3436-3441. PMID: 16627763

Nisbet-Brown, E., N.F. Olivieri, P.J. Giardina, R.W. Grady and E.J. Neufeld et al., 2003. Effectiveness and safety of ICL670 in iron-loaded patients with thalassaemia: A placebo-controlled, dose-escalation trial. Lancet, 361: 1597-1602. PMID: 12747879

O'Brien, T.J., S. Ceryak and S.R. Patierno, 2003. Complexities of chromium carcinogenesis: Role of cellular response, repair and recovery mechanisms. Mutat. Res., 533: 3-36. PMID: 14643411

Saljooghi, A.S. and S.J. Fatemi, 2010. Clinical evaluation of deferasirox for removal of cadmium ions in rat. Biometals, 23: 707-712. DOI: 10.1007/s10534-010-9337-x

Steinhauser, S., U. Heinz, M. Bartholoma, T. Weyhermuller and H. Nick et al., 2004. Complex formation of ICL670 and related ligands with Fe(III) and $\mathrm{Fe}(\mathrm{II})$. Eur. J. Inorgorganic Chem., 21: 41774192. DOI: $10.1002 /$ ejic. 200400363

Tubafard, S. and S.J. Fatemi, 2008. Chelation of bismuth by combining desferrioxamine and deferiprone in rats. Toxicol. Indus. Health, 24: 235-240. DOI: 10.1177/0748233708095771

Tubafard, S., S.J. Fatemi, A. Shokooh Saljooghi and M. Torkzadeh, 2010. Removal of vanadium by combining desferrioxamine and deferiprone chelators in rats. Med. Chem. Res., 19: 854-863. DOI: $10.1007 / \mathrm{s} 00044-009-9235-3$

Voskaridou, E., D. Christoulas and E. Terpos, 2011. Successful chelation therapy with the combination of deferasirox and deferiprone in a patient with thalassaemia major and persisting severe iron overload after single-agent chelation therapies. Br. J. Haematol., 154: 654-656. DOI: 10.1111/j.13652141.2011.08626.x

Yang, L.P.H., S.J. Keam and G.M. Keating, 2007. Deferasirox: A review of its use in the management of transfusional chronic iron overload. Drugs, 67: 2211-2230. PMID: 17927285 